\title{
Tolerância à Inundação: Aspectos da Anatomia Ecológica e do Desenvolvimento de Sesbania virgata (Cav.) Pers. (Fabaceae)
}

\author{
Viviane M. Davanso-Fabro*, Moacyr E. Medri, Edmilson Bianchini, José A. Pimenta \\ Departamento de Biologia Animal e Vegetal, Centro de Ciências Biológicas, Universidade Estadual de Londrina, \\ Caixa Postal 6001, 86051-970 Londrina, PR, Brasil.
}

\begin{abstract}
Twenty days seedlings of Sesbania virgata (Cav.) Pers. (Fabaceae) cultivated in green house were flooded by forty days. Flooded plants presented increasing of dry weight and lenght, evident cortical fissures and spongy cortical swelling on the stem basis and root, superficial roots on the soil and adventitious roots. It is possible that the morpho-anatomic plasticity presented by this specie is contribuiting for its hipoxic soils stablishment.
\end{abstract}

Key words: Sesbania virgata, Hipoxia, Ecological Anatomy.

Palavras-chave: Sesbania virgata, Hipoxia, Anatomia Ecológica.

\section{INTRODUÇÃO}

Existem basicamente duas interpretações sobre as estratégias de tolerância das plantas à hipoxia. Uma considera que, quando inundadas, as plantas ativariam rotas metabólicas que controlariam o mecanismo respiratório das raízes (Crawford, 1978). A outra considera que as plantas não necessitariam alterar seu metabolismo, porque apresentariam adaptações morfoanatômicas que possibilitariam a respiração aeróbica (Armstrong, 1979). Joly (1991), sugere que em espécies tropicais ocorrem tanto adaptações metabólicas e anatômicas, como uma interação entre elas.

As espécies variam amplamente nas respostas às condições anaeróbicas e o efeito pode mudar dependendo da idade da planta e da natureza do ambiente (Feldman, 1984). De modo geral, o alagamento produz respostas características como: redução da taxa de crescimento, intumescimento da base do caule (Pimenta et al., 1996), epinastia, senescência e abscisão precoce das folhas (Wareing \& Phillips, 1981), formação de raízes adventícias (Pimenta et al., 1994; Yamamoto et al., 1995), desenvolvimento de aerênquima (Feldman, 1984; Wiedenroth, 1993), hipertrofia de lenticelas (Medri \& Correa, 1985; Pimenta et al., 1994; Pimenta et al., 1996), enrijecimento das células do cilindro central (Schlüter et al., 1993), aumento de níveis de etileno (Feldman, 1984), redução da transpiração diminuindo o fluxo de nutrientes para as folhas (Colin-Belgrand et al., 1991) e baixa produção de biomassa (Rinne, 1990).

Sesbania virgata (Cav.) Pers. (Fabaceae), popularmente conhecida como cambaí, é uma arvoreta de aproximadamente 3 metros de altura, que habita freqüentemente beira de rios, lagoas, banhados, etc., com floração e frutificação mais intensas de setembro a novembro (Eisinger, 1984). Esta espécie é abundante na faixa de solo mais hidromórfico às margens da Represa Capivara, Município de Sertanopólis, PR. Os indivíduos produzem inúmeras raízes adventícias durante as cheias. Quando a lâmina de água abaixa, estas raízes se expõem, desidratam e morrem.

Visando ampliar os conhecimentos sobre estratégias adaptativas de plantas tropicais 
quando inundadas, estudou-se o efeito desta condição em Sesbania virgata, a partir de análises morfoanatômicas e de desenvolvimento.

\section{MATERIAL E MÉTODOS}

Sementes de Sesbania virgata foram germinadas em duas caixas plásticas com areia grossa como substrato e mantidas em casa de vegetação. Aos 20 dias de idade, as plântulas de uma das caixas foram alagadas (com lâmina d'água a cerca de $2 \mathrm{~cm}$ do substrato) por um período de 40 dias, sendo irrigadas periodicamente com solução nutritiva de Hoagland (10\%).

Para as análises anatômicas, ao final dos 40 dias de tratamento foram coletados segmentos da base do caule $(1 \mathrm{~cm}$ acima do colo - região de transição vascular entre caule e raízes) e da raiz principal $(1 \mathrm{~cm}$ abaixo do colo) de 5 plantas de cada grupo para a confecção de lâminas permanentes. Estes segmentos foram fixados em F.A.A. 70\%, desidratados, diafanizados e incluídos em paraplast. Os blocos foram seccionados à espessura de $13 \mu \mathrm{m}$. As secções foram coradas com azul de astra-fuccina básica e montadas em bálsamo do Canadá. Para estudos do xilema utilizaram-se macerados de segmentos de $1 \mathrm{~cm}$ do colo de 5 plantas de cada grupo. Todas as medidas microscópicas foram efetuadas com auxílio de ocular micrométrica. Os desenhos foram feitos em câmara clara. Determinou-se a porcentagem de espaços intercelulares corticais, por meio do método gravimétrico (Medri, 1980). As medidas celulares foram obtidas de 50 células por repetição.

No primeiro e no último dia de tratamento, mediu-se o comprimento da parte aérea e da raiz principal de plantas controle e alagadas. Estas plantas foram separadas em raízes, caules e folhas e colocadas em estufas por 72 horas, para obtenção do peso da matéria seca. Com estes dados, avaliou-se o crescimento e o desenvolvimento vegetativo comparando-se os dados obtidos das plantas controle e alagadas com os obtidos no início do experimento.

Observações morfológicas foram efetuadas semanalmente a fim de se acompanhar a possível formação de lenticelas hipertróficas, raízes adventícias, rachaduras corticais e intumescimento de caules e raízes. As análises estatísticas basearam-se na análise de variância (ANOVA), e determinou-se a DMS pelo teste "a posteriori" de Tukey ao nível de significância de $5 \%$.

\section{RESULTADOS}

As plantas alagadas de S. virgata apresentaram porcentagens de espaços intercelulares corticais significativamente maiores nos caules quando comparadas às plantas controle (Figs. 1, 2-3). Os diâmetros das células do parênquima cortical em caules e raízes foram significativamente menores nas plantas alagadas (Tabela 1). As maiores espessuras corticais das raízes e caules nas plantas alagadas (Tabela 1) podem ter sido decorrentes da expressiva formação de aerênquima nesta região, principalmente no caule (Figs. 1, 2-3) produzindo profundas rachaduras longitudinais.

$\mathrm{O}$ alagamento não alterou significativamente a relação tecido cortical / tecido vascular, mas o xilema nos caules das plantas alagadas apresentou maior grau de lignificação comparado ao controle e o tecido floemático apresentou-se menos desenvolvido (Fig. 2-3). O diâmetro médio dos elementos de vaso do caule foi maior nas plantas alagadas do que nas plantas controle, não havendo diferenças significativas quanto ao comprimento destas células (Tabela 1). 
Tabela 1. Anatomia comparada das bases da raiz principal e do caule de plantas controles e alagadas por 40 dias de S. virgata.

\begin{tabular}{lrr}
\hline \multicolumn{1}{c}{ Parâmetros avaliados } & Controle & Alagado \\
\hline & & $\mu \mathrm{m}$ \\
Diâmetro das células corticais do caule & $3,39 \mathrm{a}$ & $2,60 \mathrm{~b}$ \\
Diâmetro das células corticais da raiz principal & $3,39 \mathrm{a}$ & $3,00 \mathrm{~b}$ \\
Diâmetro do caule & $219,00 \mathrm{a}$ & $240,00 \mathrm{a}$ \\
Espessura do córtex do caule & $49,40 \mathrm{~b}$ & $71,50 \mathrm{a}$ \\
Espessura do cilindro central do caule & $60,10 \mathrm{a}$ & $48,50 \mathrm{a}$ \\
Diâmetro da raiz principal & $207,14 \mathrm{~b}$ & $356,00 \mathrm{a}$ \\
Espessura do córtex da raiz principal & $42,43 \mathrm{~b}$ & $168,00 \mathrm{a}$ \\
Espessura do cilindro central da raiz principal & $61,14 \mathrm{a}$ & $71,20 \mathrm{a}$ \\
Comprimento dos elementos de vaso do caule & $22,43 \mathrm{a}$ & $22,35 \mathrm{a}$ \\
Diâmetro dos elementos de vaso do caule & $3,31 \mathrm{~b}$ & $4,59 \mathrm{a}$ \\
\hline
\end{tabular}

* As médias seguidas da mesma letra nas linhas não diferem pelo teste de Tukey $(\mathrm{P}<0,05)$.

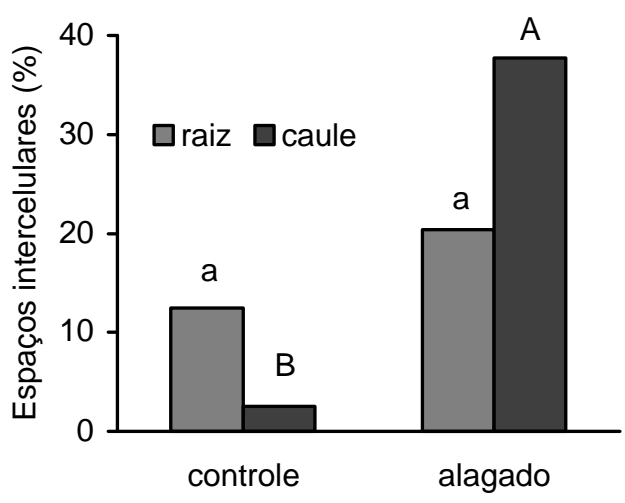

Fig. 1. Espaços intercelulares corticais em raiz e caule de plantas de Sesbania virgata, após 40 dias de tratamento. Barras seguidas de letras maiúsculas ou minúsculas iguais indicam não haver diferenças pelo Teste de Tukey $(\mathrm{P}<0,05)$.
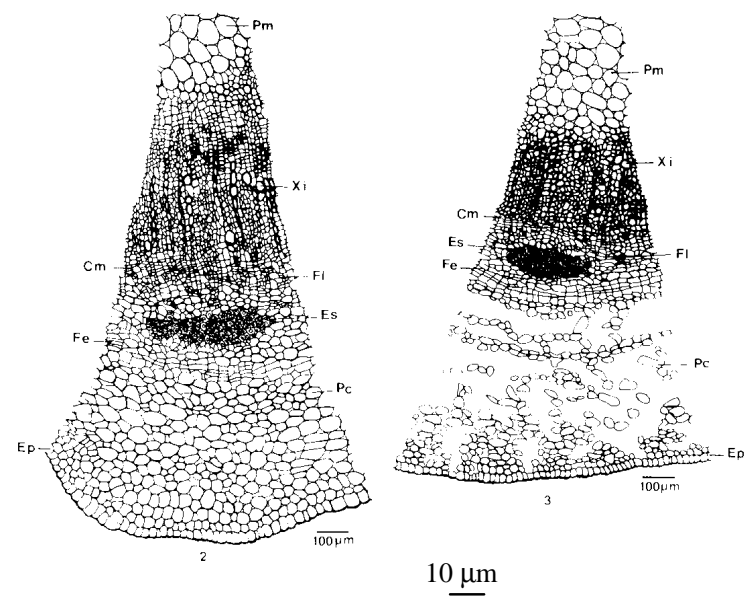

Fig. 2-3. Corte transversaı da base do caule de plântulas de Sesbania virgata, após 40 dias de tratamentos. 2. Controle. 3. Alagado. Cm:câmbio vascular. Ep:epiderme. Es:esclerênquima. Fe:felogênio. Fl:floema. Pc:parênquima cortical. Pm:parênquima medular. Xi:xilema.
O diâmetro do caule de plantas alagadas não diferiu estatisticamente das plantas controle, possivelmente porque, apesar da espessura do córtex ter sido maior, a espessura do cilindro central foi ligeiramente menor. Não houve diferenças significativas na espessura do cilindro central da raiz das plantas alagadas, mas a espessura do córtex foi significativamente maior, resultando numa maior espessura total da raiz (Tabela 1).

O peso da matéria seca das plantas alagadas foi significativamente maior do que o das plantas controle (Fig. 4).

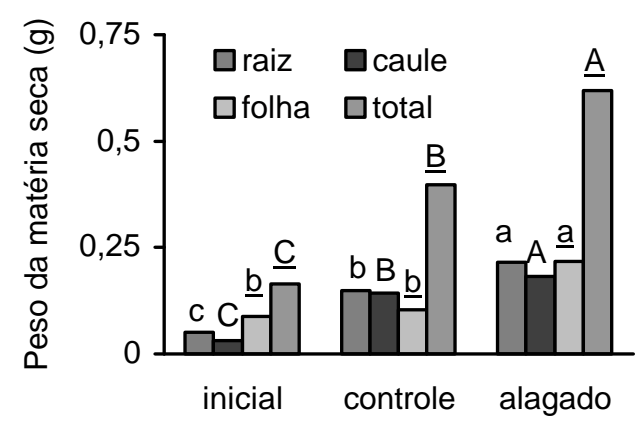

Fig. 4. Peso da matéria seca de plantas de Sesbania virgata, após 40 dias de tratamento. Barras seguidas de letras iguais indicam não haver diferenças pelo Teste de Tukey $(\mathrm{P}<0,05)$.

No início do experimento, a parte que mais contribuiu para a matéria seca total da planta foi a folha (Fig. 5). Ao final do experimento, nas plantas controle houve queda significativa na contribuição das folhas para o peso da planta, em razão da intensa abscisão (Fig. 5). 


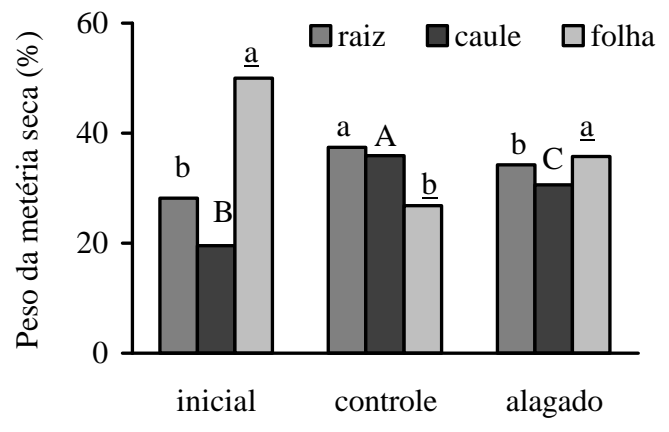

Fig. 5. Porcentagem acumulativa de peso da matéria seca de plantas de Sesbania virgata, após 40 dias de tratamento. Barras seguidas de letras iguais indicam não haver diferenças pelo Teste de Tukey $(\mathrm{P}<0,05)$.

O aumento no comprimento das plantas alagadas, comparando às plantas controle, foi maior tanto para a raiz principal como para a parte aérea (Fig. 6).

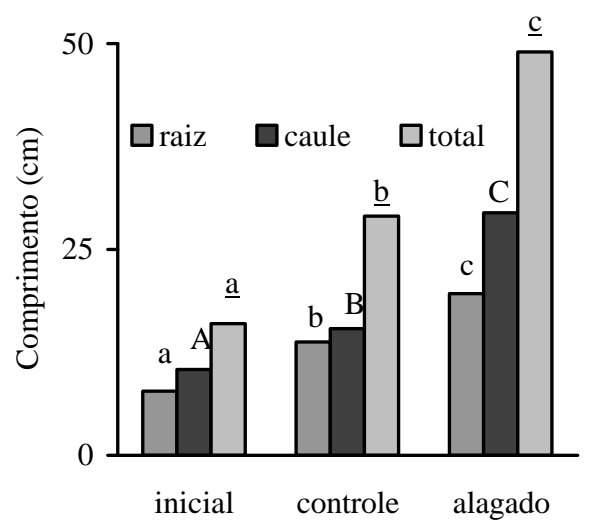

Fig. 6. Comprimento da raiz principal, da parte aérea e total de plantas de $S$. virgata, após 40 dias de tratamento. Barras seguidas por letras iguais indicam não haver diferenças pelo Teste de Tukey $(\mathrm{P}<0,05)$.

As plantas alagadas apresentaram acentuadas rachaduras corticais nas bases do caule e raiz principal, formação de aerênquima no córtex do caule e raiz principal, desenvolvimento de raízes diageotrópicas junto à superfície do solo e formação de raízes adventícias (Fig. 7-8 ).

\section{DISCUSSÃO E CONCLUSÃO}

O desenvolvimento de muitos espaços intercelulares no parênquima cortical de caules e raízes é comum em situações de anaerobiose do solo (Armstrong, 1978) e resultados semelhantes aos
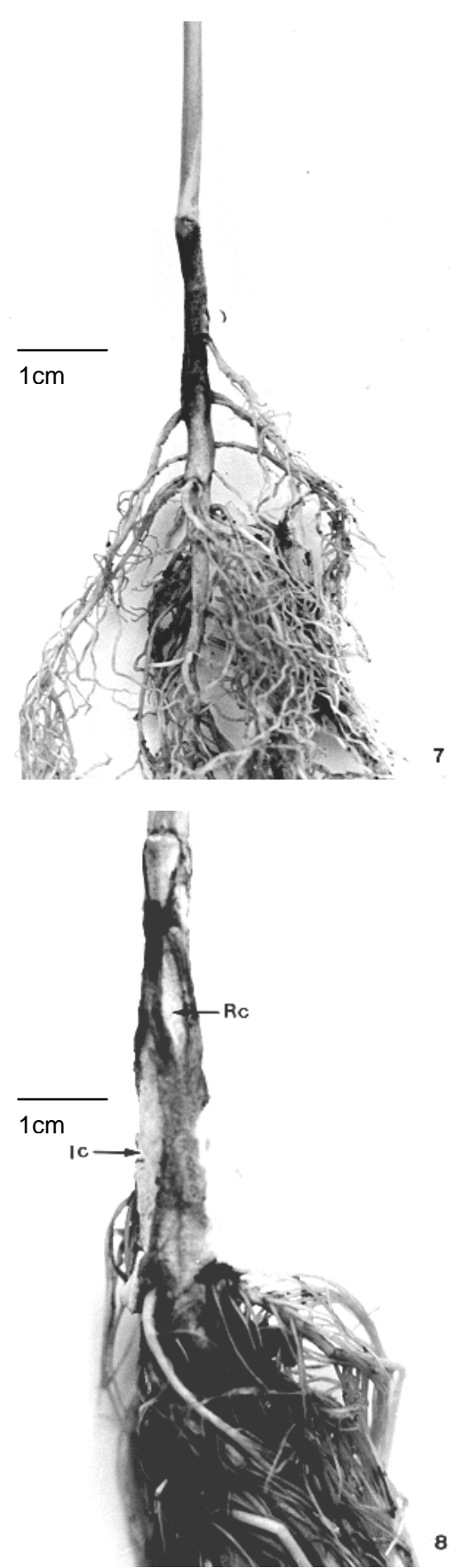

Fig. 7-8. S. virgata após 40 dias de tratamentos. 7. Controle. 8. Alagado. Rc:rachadura cortical. Ic:intumescimento cortical esponjoso.

de S. virgata foram obtidos em Spathodea campanulata (Medri \& Correa, 1985) e Jacaranda puberula (Pimenta et al., 1996). Sugere-se que em $S$. virgata, estes espaços 
intercelulares sejam esquizógenos, pois são geralmente delimitados por células intactas como descrito por Esau (1976). Segundo Armstrong (1979), os espaços intercelulares são adaptações naturais que permitem a difusão dos gases da atmosfera para as regiões submersas do sistema de raízes.

Medri \& Correa (1985) verificaram aumento no tamanho das células corticais durante $o$ alagamento em plantas de Spathodea campanulata, diferentemente do que foi observado para $S$. virgata.

O incremento no diâmetro dos elementos de vaso de plantas alagadas de $S$. virgata corroboram a afirmação de Hook \& Scholtens (1978) de que espécies arbóreas de pântanos naturais têm o diâmetro dos elementos de vaso maior do que o das células de plantas que não vivem em locais inundados. Como o diâmetro dos elementos de vaso está diretamente relacionado com a capacidade de conduzir água, os resultados obtidos indicam que pode estar havendo uma maior eficiência no transporte de água nesta espécie. Maior grau de lignificação de células do xilema em plantas alagadas também foi verificado por Schlüter et al. (1993), sugerindo que um cilindro central enrijecido proporciona resistência à pressão provocada pelo alagamento.

Joly \& Crawford (1982), estudando espécies tropicais de matas ciliares como Sebastiania commersoniana (Sin. S. klotschiana), Genipa americana e Hymenaea courbaril, verificaram que as mesmas não têm o crescimento afetado pela inundação (como verificado para $S$. virgata) classificando-as como tolerantes ao alagamento. Wit (1978) afirmou que o aumento de peso da matéria seca das raízes de plantas adaptadas à inundação, se deve ao aumento da ramificação das mesmas e à formação de raízes adventícias.

A maior contribuição da folha para o peso da matéria seca da planta no início do experimento, se deve ao fato de que ela se desenvolve estrategicamente primeiro para garantir, através da fotossíntese, o desenvolvimento da planta. Pode ainda relacionar-se à uma adaptação ao período de cheia do Rio Tibagi, quando a espécie em estudo passa submersa de 3 a 4 meses por ano, pois uma maior área foliar intensifica a captação dos raios solares, compensando uma menor incidência destes nas folhas devido à presença da lâmina d'água. A intensa abscisão apresentada pelas plantas controle durante $\mathrm{o}$ experimento, sugere que solos bem drenados provocam estresse hídrico em $S$. virgata.

O comprimento das plantas alagadas de $S$. virgata também foi maior em relação às controles. Wareing \& Phillips (1981), afirmam que em plantas que estão adaptadas a ambientes úmidos, a extensão de entrenós ocorre até mesmo mais rapidamente durante o alagamento. Portanto os dados de massa seca e comprimento obtidos para $S$. virgata, indicam que esta espécie é tolerante ao alagamento, corroborando as observações de campo sobre sua abundância em áreas alagáveis da Bacia Hidrográfica do Baixo Tibagi.

Vários autores (Pimenta et al., 1994; Pimenta et al., 1996) observaram lenticelas hipertróficas em plantas submetidas à inundação e sugeriram que estas contribuem para o aumento nas trocas gasosas entre a atmosfera e a planta. Hook \& Scholtens (1978), afirmaram que elas estão envolvidas também com a eliminação de metabólitos tóxicos, resultantes da respiração anaeróbica. Embora $S$. virgata não tenha apresentado lenticelas, as rachaduras corticais observadas nas plantas alagadas, podem estar desempenhando o mesmo papel das lenticelas hipertróficas.

O intumescimento do caule, como resposta ao alagamento também foi observado em Coleus blumei (Pimenta et al., 1994) e Jacaranda puberula (Pimenta et al., 1996). Em S. virgata este intumescimento em plantas alagadas certamente foi causado pela formação de aerênquima, que pode estar favorecendo a difusão de oxigênio. A difusão deste gás da parte aérea para o sistema de raízes provavelmente permite um metabolismo aeróbico nas raízes diageotrópicas e adventícias, o que contribui para a sobrevivência da planta durante o alagamento. As raízes adventícias observadas em $S$. virgata no campo podem contribuir para o aumento da área de absorção de oxigênio, água e íons (Wit, 1978).

S. virgata é abundante em áreas alagáveis do Baixo Tibagi, sendo tolerante à inundação. A 
análise dos resultados aqui apresentados sugere que as alterações morfo-anatômicas podem ser importantes na tolerância à inundação desta espécie, possivelmente interagindo com estratégias metabólicas.

\section{AGRADECIMENTOS}

Este estudo faz parte do projeto "Aspectos da Fauna e Flora da Bacia do Rio Tibagi", financiado pelo convênio Universidade Estadual de Londrina, Consórcio Intermunicipal para Proteção Ambiental da Bacia do Rio Tibagi COPATI e KLABIN - Fabricadora de Papel e Celulose.

\section{RESUMO}

Plantas de Sebania virgata (Cav.) Pers. (Fabaceae) cultivadas em casa de vegetação foram alagadas por 40 dias. Plantas alagadas apresentaram aumento do peso da matéria seca e comprimento, acentuadas rachaduras corticais e intumescimento cortical esponjoso em caules e raízes, raízes superficiais e raízes adventícias. É possível que a plasticidade morfo-anatômica apresentada por esta espécie esteja contribuindo para o seu estabelecimento em solos hipóxicos.

\section{REFERÊNCIAS BIBLIOGRÁFICAS}

Armstrong, W. (1978), Root aeration in the wetland condition. In: Plant Life in Anaerobic Environments, eds. Hook, D. D.; Crawford, R. M. M. Ann Arbor Science, Michigan, pp. 269298.

Armstrong, W. (1979), Aeration in higher plants. Adv. Bot. Res., 7, 225-332.

Colin-Belgrand, M.; Dreyer, E.; Biron, P. (1991), Sensitivity of seedlings from different oak species to waterlogging: effects on root growth and mineral nutrition. Ann. Sci. For., 48, 193-204.

Crawford, R. M. M. (1978), Metabolic adaptation to anoxia. In: Plant Life in Anaerobic Environments, eds. Hook, D. D.; Crawford, R. M. M. Ann Arbor Science, Michigan, pp. 119136.
Eisinger, S. M. (1984), Levantamento dos gêneros Sesbania, Indigofera e Tephrosia no Rio Grande do Sul. Tese de Doutorado, Universidade Federal do Rio Grande do Sul, Porto Alegre.

Esau, K. (1976), Anatomia das Plantas com Sementes. Edgard Blücher, São Paulo, pp. 129.

Feldman, L. P. (1984), Regulation of root development. Ann. Rev. Plant Physiol., 35, 223-242.

Hook, D. D.; Scholtens, J. R. (1978), Adaptations and flood tolerance of tree species. In: Plant Life in Anaerobic Environments, eds. Hook, D. D.; Crawford, R. M. M. Ann Arbor Science, Michigan, pp. 299-331.

Joly, C. A. (1991), Flooding tolerance in tropical trees. In: Plant Life Under Oxygen Deprivation: Ecology, Physiology and Biochemistry, eds. Jackson, M. B.; Daveis, D. D.; Lambers, H. Academic Publishing, The Hague, pp. 23-34.

Joly, C. A.; Crawford, R. M. M. (1982), Variation on tolerance and metabolic responses to flooding in some tropical trees. J. Exp. Bot., 33, 799-809.

Medri, M. E. (1980), Anatomia comparada e correlações anatomo-fisio-ecológicas de seis clones de Hevea sp. Tese de Doutorado, Universidade do Amazonas/INPA, Manaus.

Medri, M. E.; Correa, M. A. (1985), Aspectos histológicos e bioquímicos de Joannesia princips e Spathodea campanulata, crescendo em solos na capacidade de campo, encharcado e alagado. Semina, 6 (3), 147-154.

Pimenta, J. A.; Orsi, M. M.; Medri, M. E. (1994), Aspectos morfológicos e fisiológicos de .Coleus blumei Benth. submetido à inundação e à aplicação de ethrel e cobalto. Rev. Bras. Biol., 53 (4), 427-433.

Pimenta, J. A.; Medri, M. E.; Bianchini, E.; Muller, C.; Okamoto, J. M.; Francisconi, L. M. J.; Correa, G. T. (1996), Aspectos da morfoanatomia e fisiologia de Jacaranda puberula Cham. (Bignoniaceae) em condições de hipoxia. Rev. Bras. Bot., 19 (2), 215-220.

Rinne, P. (1990), Effects of various stress treatments on growth and ethylene evolution in seedlings and sprouts of Betula pendula Roth an Betula pubescens Ehrh. Scand. J. For. Res., 5, 155-168. 
Schlüter, U. B.; Furch, B.; Joly, C. A. (1993), Physiological and anatomical adaptations by young Astrocaryum jauari Mart. (Araceae) in periodically inundated biotopes of Central Amazonia. Biotropica, 25, 384-396.

Wareing, P. F.; Phillips, I. D. J. (1981), Growth \& differentiation in plants. Pergamon International Library, Oxford.

Wiedenroth, E. M. (1993), Responses of roots to hypoxia: their strutural and energy relations with the whole plant. Env. and Exp. Bot., 33, 41-51.
Wit, M. C. J. (1978), Morphology and function of roots and shoot growth of crop plants under oxygen deficiency. In: Plant life in anaerobic environments, eds. Hook, D. D.; Crawford, R. M. M. Michigan, Ann Arbor Science, pp. 332350.

Yamamoto, F.; Sakata, T.; Terazawa, K. (1995), Growth, morphology, stem anatomy, and ethylene production in flooded Alnus japonica seedlings. IAWA J., 16 (1), 47-59. 